Motrivivência Ano XXIII, No 36, P. 197-213 Jun./2011

doi: 10.5007/2175-8042.2011v23n36p197

\title{
QUANDO A BELEZA PÕE MESA: UMA ANÁLISE DAS CONDIÇÕES DE TRABALHO DO PROFISSIONAL DE EDUCAÇÃO FÍSICA EM MEGA-ACADEMIAS
}

\author{
José Carlos de Moraes Guimarães Filho' \\ Diego Luz Moura² \\ Marcelo Moreira Antunes 3
}

\section{RESUMO}

O estudo objetiva identificar as condições de trabalho dos profissionais de educação física em mega-academias do Rio de Janeiro. A metodologia utilizada foi a pesquisa de campo com 12 informantes. Encontraram-se os seguintes resultados: carga horária elevada, baixa quantidade no sono, alto esforço laboral e uma grande importância à estética corporal. Outro fator que se torna fundamental na discussão é o exacerbado culto ao corpo, visto como um modelo buscado por grande parte dos alunos dessas mega-academias. Neste contexto, o culto ao corpo é visto como capital simbólico na busca por um espaço no mercado de trabalho.

Palavras-chaves: Saúde. Condições de trabalho. Mega-academias.

1 Graduado em educação física pelo Centro Universitário da Cidade.

2 Doutorando em Educação Física (UGF). Mestre em Educação Física (UGF). Docente do Centro Universitário da Cidade (UniverCidade). Docente da secretaria Estadual e Municipal de Educação do Rio de Janeiro. Contato: lightdiego@yahoo.com.br

3 Doutorando em Educação Física (Unicamp). Mestre em educação física pela Universidade Gama Filho. Docente do curso de educação física do Centro Universitário da Cidade.

Contato: antunesmm@hotmail.com. 


\section{Introdução}

Os parâmetros de beleza foram se modificando durante a história, a partir dos valores de cada época. Deste modo, em cada período histórico se apresentava padrões estéticos, diferentes, para homens e mulheres. Na modernidade, a valorização da beleza corporal se homogeneizou e encontra respaldo em uma série de conceitos de saúde e de beleza, difundidos pela mídia, por especialistas e por atletas dos esportes de alto-rendimento (GOLDENBERG, 2002). Os equipamentos milagrosos para estética e métodos de emagrecimento são largamente veiculados pelos meios de comunicação, incutindo na sociedade a necessidade de adequação a esses valores e comportamentos atrelados a essa estética corporal.

Esta busca por um determinado padrão corporal, quer seja por saúde ou por estética, tem se refletido no aumento do número de academias de ginástica. Segundo dados apresentados por Bergallo (2004) no Brasil ainda não possuem dados estatísticos precisos, pois o mercado do fitness ainda começa a se organizar. Em levantamentos preliminares realizados com representantes em vários estados, estimamos existirem 7.000 academias em todo o país, empregando 120.000 pessoas (são atualmente 40.000 profissionais de educação física registrados nos recém-constituídos Conselhos Regionais de Educação Física). Admitindo-se uma média de 400 clientes por unidade, chegamos a um total de 2,8 milhões de pessoas freqüentando as academias $(1,6 \%$ da população) e gerando um faturamento anual de $\mathrm{R} \$ 1,5$ bilhões (estimando-se uma mensalidade média de $R \$ 45,00$ - variando de $R \$ 30,00$ a $R \$ 220,00)$. Trata-se de um mercado constituído de micro e pequenas empresas, com mínima estrutura gerencial.

Entretanto, começa a surgir a tendência das mega-academias. Estas empresas possuem gestão profissionalizada e serviço diversificado. Em conformidade ao crescimento de empreendimento onde o fitness é a tônica, surge ainda nas grandes metrópoles as Mega-academias que se tornaram o local onde os aspectos estéticos contemporâneos se consolidam como uma regra.

Diante destes aspectos, levantam-se questões fundamentais que influenciam e pressionam o desempenho profissional no ambiente das Mega-academias. Entre uma multiplicidade de fatos gerados neste contexto, interessa em particular a análise das condições de emprego com baixa remuneração, e muitas vezes sem garantias trabalhistas que 
atingem diretamente a Qualidade de Vida no Trabalho e a Saúde do Trabalhador.

Desta forma, o objetivo deste artigo é Identificar e Compreender as condições de trabalho encontradas por profissionais de Educação Física em grades academias.

\section{Metodologia}

O presente estudo se configura como uma pesquisa de campo, de característica exploratória e quantitativa. Utilizou-se como instrumento de coleta de dados um roteiro de entrevista adaptado de Espirito-Santo (2005), aplicado em 12 profissionais que atuam em uma mega-academia no bairro de Ipanema, na zona sul do município de Rio de Janeiro. O critério de seleção dos informantes foi estar formados no período máximo de 5 anos. Todos os pesquisados concordaram em participar voluntariamente da pesquisa e assinaram termo de livre consentimento.

\section{Resultados}

A seguir apresentam-se os dados referentes à pesquisa e se procede a uma discussão dos mesmos à luz de algumas categorias de análise e da literatura disponível sobre o tema. A discussão dos dados se construiu a partir das seguintes categorias: dados pessoais, escolaridade, cuidados com a saúde, rotina, acidentes de trabalho, relevância social do trabalho e percepção de esforço.

\section{Dados pessoais}

Os dados apontam para o predomínio de profissionais homens $(75 \%)$ nesta academia. Por outro lado, o estudo de Espirito-Santo (2005) pesquisando profissionais de grandes academias encontrou um público homogêneo em relação à distribuição de gênero. Portanto, podemos perceber que nesta academia especificamente parece haver uma tendência à atuação de homens no salão de musculação.

No que se refere à distribuição etária dos entrevistados, pode-se verificar o predomínio de profissionais com faixa etária entre 23 e 32 anos. De certa forma, parece que o mercado das grandes academias direciona e seleciona profissionais de menor idade quando comparado ao campo escolar, por exemplo. Estes dados podem estar relacionados com uma suposta expectativa dos frequentadores de academia sobre um determinado padrão estético. Estes dados nos remetem à reflexão sobre como o mercado está sendo construído. 
Nível de formação

Verificasse que metade (6) dos profissionais possui alguma especialização. Isto demonstra o desejo pela formação continuada, especializando-se em uma determinada área, mas por outro lado, reflete que a pós-graduação lato senso tem se consolidado como uma moeda de troca no mercado de trabalho. Em contraposição, os informantes que não possuem especialização relataram que estas não agregariam nada em termos de aumento de rendimento salarial, desprendendo um investimento não programado, cujo retorno é nulo.

\section{Cuidados com a saúde}

Os dados obtidos apontam para uma grande adesão à utilização de moderadores de apetite $(66,7 \%)$. Desses $62,5 \%$ utilizam sem orientação médica. Arrais et al (1997) indica que o número de indivíduos que se automedicam é de $91 \%$, sendo que $51 \%$ são dos que usam medicamentos por indicação de leigos e $40 \%$ usam prescrições anteriores. Entretanto, existe um paradoxo que se encaminha em sentido contrário, tendo em vista que $75 \%$ dos informantes fazem uso de hipercalóricos (suplementos alimentares). Comparando com os dados do estudo de Espirito-Santo
(2005), há uma diferença significativa quanto à utilização de moderadores de apetite. Em sua pesquisa, $46,7 \%$ faziam utilização deste composto, enquanto nesta, com 12 indivíduos chegou-se a 66,7\%. Em contrapartida pode ser observado que a utilização do produto sem recomendação médica tem um fim estético importante. Esse uso visa à manutenção da imagem corporal como capital simbólico na disputa pelo mercado de trabalho de personal trainer, haja vista que há uma procura exacerbada por profissionais esteticamente padronizados, que possibilitam a associação direta ao futuro rendimento ou ao objetivo dos clientes deste local.

Finalidade do uso da automedicação

A análise dos indivíduos que utilizam moderadores exclusivamente por automedicação observa-se que o objetivo é, em sua grande maioria $(75 \%)$, a estética. No entanto, ao analisar os indivíduos que relacionaram seu uso à saúde ( $25 \%)$, nota-se que, para estes, a saúde está diretamente relacionada ao seu desempenho no trabalho. No estudo de Arrais et al (1997) o cansaço físico é um dos motivos para a automedicação. Pode-se perceber que as três categorias: estética, saúde e desempenho, são justificativas da utilização destes suplementos e 
Ano XXIII, n 36, junho/2011

estão relacionadas à construção do corpo como capital para a disputa do mercado de trabalho.

\section{Estimulantes}

Os estimulantes são recursos exógenos que aceleram o metabolismo a fim de aumentar a atividade cardíaca, consequentemente aumentando assim, a disposição do individuo. Embora tenha sido de $50 \%$ o uso de estimulantes, observou-se na pesquisa que a cafeína $(41,7 \%)$, é quase sempre utilizada em conjunto com outra substância, mais frequentemente associada à efedrina (25\%). No entanto, a cafeína utilizada é normalmente ingerida em grandes doses de café. No estudo de Arrais et al (1997) a cafeína ocupa o terceiro lugar em ocorrência na utilização de princípios ativos sem prescrição médica. Dentre os cinco usuários que admitiram o uso, três chegaram a relatar fazer a ingestão de aproximadamente dois litros de café por dia. Em combinação com outros medicamentos. O mais comum é a sibutramina e a efedrina que pode vir a ter finalidade de emagrecimento. A cafeína associada à anfetamina $(8,3 \%)$ tem a finalidade exclusiva de estímulo visando à diminuição da sensação de sono. A utilização desses estimulantes pode estar diretamente relacionada ao baixo índice de horas de sono por noite.
Dieta alimentar

Observa-se que cerca de $58 \%$ dos informantes afirmaram não utilizar de dieta. Os $25 \%$ que seguem uma dieta prescrita por profissionais, fazem parte do grupo que utiliza moderador de apetite por recomendação profissional devido a algum distúrbio hormonal e/ou alimentar. Apenas 16\% fazem utilização de moderador de apetite juntamente com uma dieta, mesmo sem orientação profissional. Sabino, Luz e Carvalho (2010) observaram que o uso de dieta sem acompanhamento profissional é comum em academias de ginástica no Rio de Janeiro. A partir da análise desses dados questionase a hipótese se não seria melhor aliar a utilização de moderador de apetite à uma dieta equilibrada, além da não utilização de suplementos hipercalóricos como o citado 'whey protein' e a creatina.

Observa-se que $60 \%$ dos informantes que seguem uma dieta por mais de 4 anos, estão relacionados à recomendação profissional. Os demais indivíduos do estudo não mantêm a regularidade necessária ao bom resultado das dietas escoIhidas sem o auxílio de profissionais especializados.

Os dados apontaram que $50 \%$ dos profissionais não saem da academia nem para almoçar. Estes, em grande parte, se alojam em salas 
destinadas à professores ou coordenadores para fazer suas refeições. Isso se constitui como uma estratégia para a aquisição de tempo privado, pois em outros espaços seriam abordados por clientes ávidos por orientação em seus exercícios. Os demais profissionais fazem suas refeições em casa $(25 \%)$, em bares e restaurantes $(17 \%)$ e em outros lugares $(8 \%)$, demonstrando que eles também evitam o ambiente da academia no momento do almoço ou da refeição.

Os informantes comem muito rápido para cumprir carga horária imposta pelas academias. $67 \%$ gastam até 20 minutos para as refeições, e 33\% utilizam de 20 a
30 minutos para fazê-las. A alimentação é praticamente vista como um obstáculo na rotina de trabalho dos informantes. Alguns profissionais confessam que o horário de almoço muitas vezes não serve apenas para as refeições cotidianas. Em diversos momentos, quando o tempo não é apertado, há um diálogo com outros companheiros de profissão visando troca de informações e até mesmo esclarecimento de algumas dúvidas, ou conversas sobre o surgimento de novas técnicas de trabalho. Alguns ainda alegam até que comem mais rápido, não apenas por ter que assumir alguma aula coletiva ou 'aluno de personal', mas também porque 'sobra mais tempo para outras coisas'.

Tabela 1 - Utilização de substâncias lícitas e ilícitas

\begin{tabular}{|l|c|c|c|c|c|c|}
\hline \multirow{2}{*}{ Substância } & \multicolumn{6}{|c|}{ Utilização } \\
\cline { 2 - 7 } & Nunca & $\begin{array}{c}\text { Já } \\
\text { experimentou }\end{array}$ & $\begin{array}{c}\text { Uma } \\
\text { vez ao } \\
\text { ano }\end{array}$ & $\begin{array}{c}\text { Uma } \\
\text { vez ao } \\
\text { mês }\end{array}$ & $\begin{array}{c}\text { Uma } \\
\text { vez por } \\
\text { semana }\end{array}$ & Diariamente \\
\hline Álcool & 1 & 2 & 1 & 2 & 6 & - \\
\hline Cigarro & 6 & 1 & - & 1 & 1 & 3 \\
\hline Tranquilizante & 6 & 3 & - & 2 & - & 1 \\
\hline $\begin{array}{l}\text { Produto para } \\
\text { emagrecer }\end{array}$ & 4 & - & - & - & - & 8 \\
\hline Anabolizante & 6 & 1 & 2 & - & 3 & - \\
\hline Multivitamínico & 4 & 3 & 2 & 3 & - & - \\
\hline Suplementos & 3 & 2 & - & 1 & 1 & 5 \\
\hline
\end{tabular}

Com base nas informações dispostas na tabela pode-se observar que não há como afirmar que o álcool é utilizado como substância inibidora de apetite, já que seu uso se restringe a $50 \%$ da população investigada em variado período semanal. 
Em relação ao uso do cigarro, $25 \%$ usam diariamente, o que pode estar associado à utilização para redução do apetite assim como a utilização de medicamentos para emagrecimento. 9\% fazem utilização semanal e outros $9 \%$ mensal, o que novamente não pode estar associado a esta finalidade, já que a quantidade é muito menor, se comparada aos $25 \%$ que utilizam diariamente.

Outro dado interessante é o uso de tranquilizante. Apenas $25 \%$ dos informantes afirmaram ter experimentado tranquilizantes, entretanto não continuaram o seu uso. A justificativa deste comportamento pode estar ligada ao efeito sonífero do tranquilizante, e conseqüentemente a diminuição do rendimento no trabalho.

A utilização de medicamentos para emagrecimento está novamente identificada, demonstrando que $67 \%$ utilizam diariamente. Essa utilização diária está divida em grupos que foram orientados por médicos e grupos que se utilizam de automedicação.

Em relação ao uso de anabolizantes, $25 \%$ fazem a utilização semanal deste produto, o que coloca em cheque a saúde, já que o uso prolongado pode acarretar diversos problemas como disfunção hormonal, problemas cardíacos e coronarianos, entre outros, como é apresentada na literatura sobre o tema. Se somado ao grupo que diz utilizar anualmente, chegamos a $42 \%$ de utilização de esteróides anabolizantes. Segundo Iriart et al (2009) o uso de anabolizantes sem caráter terapêutico aumentou significativamente entre indivíduos os jovens na atualidade, este fato concorda com os dados descritos no presente estudo, onde a faixa etária dos informantes se encontra entre 23 a 32 anos. Ainda de acordo com os autores nos Estados Unidos existem cerca de 3 milhões de indivíduos utilizando anabolizantes. No Rio de Janeiro o uso de anabolizantes se concentra predominantemente entre indivíduos que frequentam academias de ginástica, mais especificamente os que praticam musculação (IRIART et al, 2009). Portanto, localizamos a prevalência da utilização do uso de anabolizantes em academias de ginástica, o que pode indicar uma cultura que se estabelece e influência a maioria dos atores sociais deste contexto. Sabino, Luz e Carvalho (2010) reforçam essa idéia apontando a existência do hábito do uso de anabolizantes em academias de ginástica como coadjuvante das dietas que são utilizadas amplamente neste ambiente.

A utilização de multivitamínico foi descrita como esporádi$\mathrm{ca}$, apenas quando se encontravam 
doentes, normalmente com gripes e resfriados, o que indica o uso relativamente frequente quando somamos utilização mensal e anual de $42 \%$. No estudo de Arrais et al (1997) o uso de vitaminas ocupa o $5^{\circ}$ lugar no ranking dos medicamentos utilizados sem prescrição médica no Brasil. Isso representa um risco para saúde, mesmo se utilizado de forma esporádica.

Como apresentado anteriormente, $42 \%$ dos informantes fazem uso de hipercalóricos diariamente, $8 \%$ semanalmente, $8 \%$ mensalmente, $17 \%$ apenas experimentou e $25 \%$ nunca utilizaram. Questiona-se novamente a utilização de hipercalóricos em conjunto com medicamentos para emagrecimento. Talvez seja a utilização destes suplementos que estejam auxiliando o ganho de peso, juntamente com uma alimentação inadequada.

Destes dados o que se deve destacar é que a maior incidência de utilização de substâncias lícitas ou ilícitas está relacionada com o objetivo de melhorar a estética corporal.

Tabela 2 - Concepção de saúde

\begin{tabular}{|l|c|c|}
\hline Conceito de saúde & Incidência & $\mathbf{( \% )}$ \\
\hline Desempenho & 9 & 47,4 \\
\hline Estética & 5 & 26,2 \\
\hline Bem estar & 2 & 10,5 \\
\hline Boa forma & 1 & 5,3 \\
\hline Auto estima & 1 & 5,3 \\
\hline Saúde & 1 & 5,3 \\
\hline
\end{tabular}

Podemos observar que os informantes apresentaram respostas variadas sobre a concepção de saúde, inclusive mais de uma resposta para a questão. A maior incidência estava relacionada com o 'desempenho' seguido pela 'estética'. Estas respostas sinalizam um dado que provoca uma preocupação, pois o 'desempenho' relatado pelos informantes foi explicado durante a entrevista como uma melhora no rendimento do trabalho. Em consonância, a categoria 'estética', também, está relacionado com o rendimento no trabalho, pois possuir um determinado padrão estético é um meio de entrada e uma necessidade para permanência neste mercado de trabalho.

O conceito de saúde foi inicialmente definido como "um 
estado de completo bem-estar físiCo, mental e social e não apenas a ausência de doença ou enfermidade" (ORGANIZAÇÃO MUNDIAL DA SAÚDE, apud LEWIS, 1986, p.1100). Neste sentido, Palma (2000) aponta que este clássico conceito conduz para análises reducionistas, uma vez que: a) as doenças decorrem de determinismos biológicos; b) o foco é centrado no indivíduo; e, c) a ausência de doenças é o "marcador" da saúde. Portanto, conceituar "saúde" é uma tarefa árdua, pois os conceitos aparecem frágeis, não tão bem delimitados.

$\mathrm{Na}$ tentativa de romper este conceito começou-se a ser introduzido uma concepção de saúde estreitamente relacionado como um direito à cidadania, pois possibilitou uma reflexão do impacto dos fatores socioeconômicos, na medida em que, os fatores de risco não são suficientes para explicar as variações de mortalidade e morbidade desta sociedade (MINAYO; HARTZ; BUSS, 2000). Todavia, há uma série de dificuldades de mensuração dos aspectos socioeconômicos o que evidencia uma dificuldade significativa em mensurar a saúde. Portanto, saúde é um tema multifatorial.

Nas respostas dos indivíduos podemos perceber uma relação da saúde com esta perspectiva multifatorial. Entretanto, se por um lado as respostas dos informantes não restringe saúde com ausência de doença, por outro lado, acaba se restringindo a concepção de saúde como desempenho no trabalho. Portanto, a concepção de saúde está atreladas a imagem do corpo e da beleza como capital de trabalho.

Cuidados com a saúde dos alunos

Os dados indicam que $66 \%$ recomendam suplementação alimentar para seus clientes, tais como 'Whey Protein' e Creatina. Dentro desses $66 \%$, cerca de $42 \%$ recomendam mais de um suplemento.

O interessante é perceber que é socializado no campo profissional que o professor de educação física não possui competência para prescrever suplementos alimentares para seus clientes. Entretanto, mais da metade dos professores entrevistados prescrevem suplementos diversos para seus alunos.

Questiona-se se não seria melhor tanto para o treinamento quanto para o bem estar do aluno que esta indicação partisse de um nutricionista, e que este trabalhasse diretamente em contato com o educador físico, a fim de objetivar e aperfeiçoar os resultados propostos.

Com base nessa primeira parte dos dados coletados, podese observar que o educador físico atuante em mega-academias tende 
a fazer maior uso de medicamentos e suplementos, com o objetivo de obter melhor performance para o trabalho, e consequentemente aumento no rendimento salarial, porém para este fim prioriza-se a estética corporal em detrimento da saúde.

Rotina de trabalho

De acordo com os dados coletados pode-se verificar que $58 \%$ dos informantes possui de 1 a 4 clientes em aulas personalizadas e que os outros $42 \%$ possuem de 5 a 10 clientes nessa condição. Percebe-se que todos os entrevistados possuem clientes em aulas personalizadas, demonstrando que este mercado tem se tornado grande atrativo para os profissionais de educação física a buscarem as grandes academias. Essa atividade se torna mais atraente que as demais por representar ganhos relativamente mais altos em relação às aulas coletivas.

Em relação à distribuição de locais de trabalho por profissional os dados indicam que cerca de $84 \%$ trabalha entre 2 e 5 locais diferentes. Entretanto, trabalhar em mais locais não está associada a uma carga horária menor de trabalho, já que esta carga horária é divida entre as aulas coletivas e as atividades de personal trainer. Com isso observamos que há uma necessidade de rotatividade entre os profissionais visando o aumento do número tanto de aulas coletivas quanto de personalizadas com o objetivo de uma maior sustentabilidade e segurança financeira que acreditamos ser maior com o aumento das aulas coletivas que são fixas quanto o aumento do personal que é instável.

Horas trabalhadas por dia

Percebe-se pelos dados coletados que a carga horária empreendida pelos informantes se encontra acima daquela do trabaIhador convencional, chegando a mais de 12 horas diárias. Apenas $16,7 \%$ dos informantes trabalham até o limite de 8 horas por dia, os demais se dividem em jornadas de trabalho que duram de 8 a 12 horas $(33,3 \%)$ e de mais de 12 horas por dia (50\%). Esses números diários se projetam para jornadas semanais de trabalho na faixa de até 90 horas quando consideramos que muitos dos informantes trabalham inclusive sábados e domingos. Existe um efeito perverso que possibilita tais números. Embora a função de personal trainer seja o elemento que proporciona ganhos mais altos também é aquele que é mais instável obrigando os profissionais acumular vários clientes prevendo possíveis desistências. Apesar das aulas coletivas possuírem uma rentabilidade 
Ano XXIII, n ${ }^{\circ}$ 36, junho/2011

menor, há uma segurança maior quanto à manutenção de turmas nos períodos de 'baixa' como natal, reveillon, carnaval e férias de fim de ano, pois as academias mantêm os ganhos dos profissionais de aulas coletivas durante esses períodos.

Horas de sono

É socializado que o ideal seria no mínimo 8 horas de sono para uma vida saudável, entretanto nenhum dos informantes se coaduna a este perfil. $41,7 \%$ deles dormem em média de 5 a 7 horas por noite, $50 \%$ dormem de 3 a 5 horas por noite e $8,3 \%$ apenas de 1 a 3 horas de descanso por noite. Esses dados reforçam o apresentado anteriormente sobre a carga horária de trabalho, construído um perfil de profissional que trabalha excessivamente e descansa muito pouco, o que contradiz todos os preceitos para a boa saúde e para o desempe- nho profissional adequado.

Tempo de lazer semanal

Mais uma vez observa-se a intima relação entre lazer e a carga horária de trabalho. Quanto maior a carga horária, menor o tempo destinado ao lazer. Dentre todo o grupo, somando os indivíduos que praticam atividades de lazer menos de uma hora e os que praticam entre uma e três horas temos $75 \%$, onde o tempo, em média, não passa de 2 horas e a atividade mais comum é o breve cochilo. Notemos que o sono pode ser também considerado uma atividade de lazer compensatória. Este fato demonstra que o cochilo é uma estratégia de adaptação à rotina, sendo utilizado em momentos sem atividade, como quando falta algum cliente de personal. Outros 25\% dedicam-se ao lazer o tempo de 3 a 7 horas semanais, sendo $16,7 \%$ de 3 a 5 horas e $8,3 \%$ de 5 a 7 horas.

Tabela 3 - Atividades realizadas como lazer

\begin{tabular}{|l|c|c|}
\hline \multicolumn{1}{|c|}{ Atividades de lazer } & Incidência & $(\mathbf{\%})$ \\
\hline Musculação & 12 & 31,6 \\
\hline Corrida & 11 & 29,0 \\
\hline Alongamento & 4 & 10,5 \\
\hline Ginástica & 3 & 7,9 \\
\hline Natação & 2 & 5,3 \\
\hline Muay Thai & 2 & 5,3 \\
\hline Futebol & 1 & 2,6 \\
\hline Pilates & 1 & 2,6 \\
\hline Spinning & 1 & 2,6 \\
\hline Yoga & 1 & 2,6 \\
\hline
\end{tabular}


Os informantes apontaram que a corrida está sempre relacionada à musculação. Ambas foram assinaladas por quase todos os entrevistados. E a maior parte das atividades é realizada nas academias, demonstrando que nem nos raros momentos de lazer os informantes se ausentam do local de trabalho.

Com base nestes dados de seleção de atividades dentro do local de trabalho, questiona-se se essa escolha não estaria diretamente relacionada à observação de outros companheiros de profissão durante $o$ trabalho com objetivo de uma possível comparação e aprendizagem.

Acidentes e doenças relacionados ao trabalho

Podemos observar que 5 informantes tiveram algum acidente relacionado ao trabalho. É importante salientar que, não existe uma política de saúde do trabalhador no local observado. O que nos remete a um número tão alto quanto este de indivíduos que tiveram doenças relacionadas ao trabalho. Dos 5 que possuíram doenças de trabalho, 2 ficaram com alguma sequela como tendinite e bursite.

As principais doenças de trabalho que podem acometer os profissionais de educação física em academias de ginástica estão ligados com a voz e audição, pois existe uma cultura do Fitness, onde os professores sentem-se obrigados a elevarem o som das músicas por exigência dos próprios alunos ou da cultura do Fitness (PALMA et al, 2009).

O ruído vem sendo reconhecido como um agente nocivo à saúde que vem sido reconhecido como objeto de atenção da saúde pública. Entretanto, não encontramos na legislação brasileira nenhuma restrição de nível de ruídos, em atividades de lazer e academias diferente do que ocorre em alguns estados americanos ${ }^{4}$.

No que se refere a audição Lacerda, Morata e Fiorini (2009) investigando um grupo de 32 professores de academias apontou que estes apresentam queixas orgânicas auditivas possivelmente relacionadas ao nível de pressão sonora. Dentre as queixas relatadas destacam-se a sensação de ouvido tampado e a dificuldade de concentração, sintomas que são geralmente encontrados em operários fabris. Segundo os autores os resultados apontam a presença de níveis de pressão sonora acima dos padrões de conforto acústico definidos pela norma 10151 da ABNT. Neste mesmo sentido, Deus e Duarte (1997) pesquisando professores de 
academias indicaram que $86 \%$ das academias de Florianópolis tiveram valores médios acima do nível permitido. E que $21 \%$ dos professores relatam sentir desconforto auditivo mesmo após a aula.

Já no que tange à voz diversos estudos relacionam esse aspecto da saúde do professor com o ruído no ambiente de trabalho e suas consequências. Esses estudos apontam que este é um ponto sensível à saúde do professor e que de acordo com Simões e Latorre (2006) os problemas de voz, somados a outras dificuldades da vida profissional dificultam o seu desempenho laboral.

Segundo Simões e Latorre (2006) o ruído no ambiente de trabalho força o professor a fazer um ajuste negativo de sua voz proporcionando o desgaste do aparelho fonador e consequentemente um quadro sintomático que progride lentamente até o prejuízo de sua função vocal. Com isso concordam Soares e Brito (2006, p.506) quando afirmam que "As alterações da qualidade da vocal ocorrem, na maioria das vezes, de forma lenta e gradual e o indivíduo pode não perceber as modificações da voz [...]". Para Simões e Latorre (2006) o uso da voz na presença de ruído é um dos motivos do desgaste do aparelho fonador e da perda da saúde vocal.

Os sintomas comuns relacionados ao problema de voz comumente relatados em estudos com professores e profissionais da voz são rouquidão, fadiga vocal, sensação de pressão na garganta, variação entre grave e agudo, perda de voz, pigarro, dor ao falar, secura e ardor na garganta (SIMÕES; LATORRE, 2006; SOARES; BRITO, 2006; GASPARINI; BARRETO; ASSUNÇÃO, 2005)

No que se refere às doenças de trabalho, $50 \%$ dos informantes afirmam que já tiveram alguma doença relacionada diretamente a rotina e condições do trabalho. Entretanto, todos continuaram trabalhando mesmo doentes. Dentre as doenças citadas, foi comum observar casos de gripes e resfriados. Dados semelhantes foram encontrados no estudo de Deus e Duarte (1997), que encontraram um alto grau de queixas de gripes acompanhados de rinite e sinusite. Em casos mais sérios, foram citadas doenças como: laringofaringite e dermatite de contato, ou seja, os profissionais entravam em um ambiente fechado, com ar condicionado e continuavam a proliferar as doenças adquiridas, provavelmente no mesmo lugar.

$\mathrm{O}$ fato de tais profissionais trabalharem mesmo doentes está relacionado com descontos salariais, na medida em que as academias não assinam carteira de trabalho. Desta forma, toda falta independente do 
motivo resulta em descontos, somado com os descontos referentes aos clientes de personal, que são os maiores rendimentos destes professores. É possível identificar que há um sistema perverso que se contrapõe ao discurso de saúde e a manutenção de um padrão de vida considerado saudável. De acordo com Milano, Palma e Assis (2007) um dos fatores que podem explicar a ocorrências de agravos à saúde é o desgaste no trabalho relacionados a intensificação do esforço físico devido acumulação das cargas de horas trabalhadas.
O crescimento na empresa e importância social

Quando indagados sobre a possibilidade de ascensão na empresa apenas $17 \%$ acreditam que exista essa possibilidade, embora não achem que essa forma seja a melhor maneira de ascensão profissional. Consideraram como pouca possibilidade de crescimento na empresa $75 \%$ dos informantes e $8 \%$ afirmaram que não existe nenhuma chance de crescerem onde trabalham.

\section{Tabela 4 - A percepção sobre o crescimento profissional}

\begin{tabular}{|l|c|c|}
\hline \multicolumn{1}{|c|}{ Percepção sobre o crescimento profissional } & Ocorrência & (\%) \\
\hline Reconhecimento dos clientes & 5 & 41,7 \\
\hline Aumento do número de personais & 3 & 25 \\
\hline Aumento da carga horária & 3 & 25 \\
\hline Assumir um cargo de gerência & 1 & 8,3 \\
\hline Totais & 12 & 100 \\
\hline
\end{tabular}

Com possibilidade de respostas múltiplas, o aumento do número de personal, estava quase sempre relacionado ao maior reconhecimento dos clientes.

Como foi apresentado anteriormente, os $17 \%$ que apontam 'muita possibilidade de crescimento na empresa' indicam como possibilidades de crescimento assumir um cargo de gerência e o aumento da carga horária. Este último é visto de forma negativa por já obterem uma jornada de trabalho alta, seja nesta mega-academia ou em outras. O que é apontado como melhor forma de crescimento é o aumento do número de atividade personal, se apresentando como o objetivo de todos os entrevistados.

\section{Considerações Finais}

Através dos dados coletados pôde-se observar que o profissional de educação física tende a 
abrir mão da própria saúde, fazendo uso de medicamentos e drogas que melhorem a estética corporal e tornem eficaz a sua produtividade no trabalho, além dos hábitos alimentares, de sono e de lazer. Esse comportamento se reflete pelas cargas horárias extremamente elevadas, diferentes de outros trabalhadores, no apelo extremo do aumento dos rendimentos, na necessidade da manutenção de uma boa aparência e estética corporal, se adequando a um determinado padrão preestabelecido, a necessidade desse profissional se manter acordado e atento a tudo o que ocorre no seu ambiente de trabalho, o que o obriga a um esforço físico adicional durante a execução de suas tarefas laborais.

Verificou-se que as condições de trabalho são complexas, visto os altos índices de doenças relacionadas ao trabalho, o alto nível de esforço da atividade, longas jornadas de trabalho, diminuto tempo de atividades relacionadas ao lazer e o reduzido tempo de sono. $\mathrm{Na}$ perspectiva dos informantes do presente estudo o profissional descuida-se da sua saúde para aumentar os rendimentos salariais, por meio do aumento quantitativo de clientes de atividades personal e de aulas coletivas. Desta forma, questionamos: seria este mercado que aspiramos para o campo da educação física? Cabe aqui a sugestão para a ampliação de estudos dessa natureza no sentido de se ampliar a compreensão do campo de trabalho dos professores de educação física atuantes em academias de ginástica ou mesmo nas mega-academias.

A partir dos dados analisados, pode-se pensar que há a necessidade de implantação de uma política de qualidade de vida no trabalho para os profissionais de educação física, como já acontece em diversas empresas, porém essa política poderia ser adotada não apenas pelas mega-academias, mas também pelas diversas academias de portes variados, no sentido de ofertar uma ambiente laboral adequado aos princípios da qualidade de vida tão proferida nos dias atuais.

\section{Referências}

BERGALLO, C.H. Uma breve panorâmica da indústria do Fitness. ASSOCIAÇÃO BRASILEIRA DE ACADEMIAS. Rio de Janeiro, 2004. Disponível em: http://www.acadbrasil.com. br/artigos/artigos_mercado_01. htm. Acesso em: 10 de junho de 2010.

ARRAIS, P.S.; COELHO, H.L.L.; BATISTA, M.C.D.S.; CARVALHO, M.L.;RIGHI, R.E.; ARNAU, J.M. Perfil da automedicação no Brasil. Rev. Saúde Pública. v.31, n.1, p.71-7, Janeiro, 1997. 
DEUS, M. J, DUARTE, M. F. S. Nível de pressão sonora em academias de ginástica e a percepção auditiva dos professores. 2(2):5-16, $\boldsymbol{R e v}$ Bras Ativ Fis Saúde, 1997. ESPÍRITO-SANTO, Giannina do. Representações sociais da saúde dos professores de Educação Física que atuam em academias do Rio de Janeiro. Dissertação de mestrado, Programa de Pós-Graduação Stricto Sensu em Educação Física, Universidade Gama Filho, Rio de Janeiro, 2005.

GASPARINI, S.M.; BARRETO, S.M.; ASSUNÇÃO, A.A. O professor, as condições de trabalho e os efeitos sobre sua saúde. Educação e Pesquisa. São Paulo, v.31, n.2. p.189-99, maio/agosto, 2005.

GOLDENBERG, M. (org.). Nu e Vestido: dez antropólogos revelam a cultura do corpo carioca. Rio de Janeiro: Record, 2002.

IRIART, Jorge Alberto Berstein; CHAVES, José Carlos; ORLEANS, Roberto Ghignone de. Culto ao corpo e uso de anabolizantes entre praticantes de musculação.

Cad. Saúde Pública, Rio de Janeiro, v.25, n.4, p.773-82, abr, 2009.

LACERDA, A.B.M.; MORATA, T.C.; FIORINI, A.C. Características dos níveis de pressão sonora em academias de ginástica e queixas apresentadas por seus professores. Revista Brasileira de Otorrinolaringologia, v.67, n.5, p. 656-59, 2001.

LEWIS, A. Saúde. In: SILVA, B., org. Dicionário de ciências sociais. Rio de Janeiro, Fundação Getúlio Vargas, 1986. p.1099-101.

MILANO, F; PALMA, A; ASSIS, M. Saúde e trabalho dos professores de educação física que atuam com ciclismo indoor. Lect Educ Fis Deportes. [Internet] 2007 [citado 2007 out 25];12(109). Disponível em: http://www. efdeportes.com/efd109/saudee-trabalho-dos-professores-deeducacao-fisica-que-atuam-comciclismo-indoor.htm

MINAYO MCS, Hartz ZMA, Buss PM. Qualidade de vida e saúde: um debate

Necessário. v.5, n.1, Ciência \& Saúde Coletiva 2000.

OLIVEIRA, Alexandre Palma de. Atividade física, processo saúdedoença e condições sócioeconômicas: uma revisão da literatura. Revista Paulista de Educação Física, São Paulo, v. 14, n. 1, p. 97-106. jan./jul. 2000

PALMA, A; MATTOS, U. A; ALMEIDA, M. N. OLIVEIRA, G. E. M. C. Nível de ruído no ambiente de trabalho do professor de educação física em aulas de ciclismo indoor. V. 43, n.2, Rev Saúde Pública, 2009.

SABINO, C.; LUZ, M.T.; CARVALHO, M.C. O fim da 
comida: suplementação alimentar e alimentação entre frequentadores assíduos de academias de musculação e fitness do Rio de Janeiro. História, Ciência, SaúdeManguinhos. Rio de Janeiro, v.17, n.2, p.343-56, abr-jun, 2010. SIMÕES, M.; LATORRE, M.R.D.O. Prevalência de alteração vocal em educadoras e sua relação com a auto-percepção. Revista de Saúde Pública. São Paulo. v.40, n.6, p.1013-8.

SOARES, E.B.; BRITO, C.M.C.P. Perfil vocal do guia de turismo. Revista CEFAC. São Paulo, v.8, n.4, p.501-8, out-dez, 2006.

\section{ABSTRACT}

This study aims to identify the working conditions of physical education professional in mega-gyms academy of Rio de Janeiro. The methodology was base on field research with 12 informants. We found the follows results: high workload, low on sleep quality, high work effort and a great importance to body esthetics. Another factor that becomes crucial in the discussion is the exaggerate cult of the body, seen as a model persecuted by most students of theses mega-gyms. In this context, the cult of the body is seen as symbolic capital in search of a place in the labor market.

Keywords: Health. Conditions of work. Mega-gyms.

Recebido: março/2011

Aprovado julho/2011. 